\title{
Receptor expression in synovial fluid neutrophils from patients with rheumatoid arthritis
}

\author{
Fiona Watson, John J Robinson, Mark Phelan, Roger C Bucknall, Steven W Edwards
}

\begin{abstract}
Objectives-The aim of this study was to determine if neutrophils isolated from the blood and synovial fluid of patients with rheumatoid arthritis had patterns of receptor expression resembling those of blood neutrophils from controls which had been activated and primed in vitro. Methods-Fluorescence activated cell sorting was used to measure receptor expression in paired blood and synovial fluid neutrophils from patients and in control neutrophils exposed to phorbol myristate acetate and granulocytemacrophage colony stimulating factor.

Results-There was no significant difference in the patterns of receptor expression in blood neutrophils from patients and healthy controls, but neutrophils in the synovial fluid had been primed and activated within the joint. About $50 \%$ of rheumatoid synovial fluid neutrophil samples expressed Fc $\gamma$ RI, a high affinity receptor for monomeric IgG, which is only expressed in neutrophils exposed to cytokines.

Conclusions-Synovial fluid neutrophils are activated and primed within the inflamed joint and hence their ability to respond to activating factors such as immune complexes will be modulated. As the expression of $F c \gamma$ RI requires active biosynthesis, this work indicates that selective gene activation occurs when neutrophils are recruited into rheumatoid joints.
\end{abstract}

(Ann Rheum Dis 1993; 52: 354-359)

Department of

Biochemistry,

University of

Liverpool, PO Box 147,

Liverpool L69 3BX,

United Kingdom

F Watson

J J Robinson

$S$ W Edwards

Rheumatic Diseases

Unit, Royal Liverpool

Hospital, Prescott

Road, Liverpool

L69 3BX, United

Kingdom

$M$ Phelan

R C Bucknall

Correspondence to:

Dr Edwards.

Accepted for publication

30 December 1992
During the active phase of rheumatoid arthritis (RA), neutrophils constitute between 60 and $80 \%$ of the total cell population of synovial fluid. ${ }^{1}$ Neutrophils are cells of considerable cytotoxic potential and their inappropriate activation has been implicated in the pathogenesis of RA, perhaps through the generation of reactive oxygen metabolites such as hydrogen peroxide. ${ }^{2}$ Tissue damage may be promoted indirectly by the extracellular leakage of toxic products from accumulated neutrophils. ${ }^{3}$ Indeed, oxidant damaged products are present in synovial fluid ${ }^{4}$ and the oxidase function of neutrophils isolated from synovial fluid has been downregulated, indicating that reactive oxidant generation has been activated in vivo. ${ }^{5}$ Furthermore, synovial fluid from patients with RA contains myeloperoxidase in a molecular form indicating that it has been co-secreted from neutrophils concomitant with reactive oxidants. $^{6}$ The mechanisms by which neutrophils are activated within rheumatoid joints and the synovial fluid factors which result in such activation are incompletely defined.

The function of neutrophils in vivo is regulated by the levels of expression of specific plasma membrane receptors including those for complement components (CR1 and CR3) and IgG molecules (Fc RI, II, and III). On cellular activation the complement receptors are upregulated whereas Fc RIII is shed from the surface of the cell ${ }^{7}$ : Fc RII expression remains constant after cell activation whereas $\mathrm{Fc} R \mathrm{R}$ is only expressed after in vitro culture of the neutrophils with interferon $\gamma .{ }^{9}$ Neutrophil function is also regulated by the activities of cytokines such as granulocyte-macrophage colony stimulating factor (GM-CSF), tumour necrosis factor, and interferon $\gamma$ which prime the cells into a state of enhanced responsiveness. On priming, reactive oxidant production is increased together with the levels of expression of several surface receptors. ${ }^{10-12}$ As such cytokines have been found in the synovial fluid of patients with $\mathrm{RA},{ }^{13}$ it is likely that these or other similarly acting agents will upregulate neutrophil function in situ within inflamed joints.

In this work we studied the expression of neutrophil plasma membrane receptors using monoclonal antibodies and fluorescence activated cell sorting (FACS) analysis in paired bloodstream and synovial fluid neutrophils from patients with RA. We propose that the changes in membrane expression observed in synovial fluid neutrophils may be caused by the presence of activating factors, perhaps functioning in combination with cytokines within the synovial fluid, to modulate neutrophil responsiveness.

\section{Subjects and methods}

PATIENTS

Twelve patients (two men, 10 women) with seropositive RA were studied. Six patients were receiving non-steroidal anti-inflammatory drugs (NSAIDs), one in combination with sulphasalazine. Two patients were receiving prednisolone and three were not receiving any treatment at the time of study. In addition, one patient with seronegative arthritis and another with psoriatic arthritis (both receiving NSAIDs) were studied. 


\section{CELL PREPARATION}

Isolation from blood

Neutrophils were isolated from the venous blood of healthy volunteers and rheumatoid patients using dextran sedimentation followed by density gradient centrifugation on FicollPaque as described previously. ${ }^{14}$ Contaminating erythrocytes were eliminated by hypotonic lysis for 25 seconds in glass distilled water, tonicity being restored by the addition of a $9 \% \mathrm{w} / \mathrm{v}$ sodium chloride solution to give a final concentration of $0.9 \%$.

\section{Isolation from synovial fluid}

Synovial fluid was filtered through gauze and spun at $2000 \mathrm{rev} / \mathrm{min}$ for 10 minutes. Neutrophils were obtained from the resulting cell pellet using the Ficoll-Paque separation procedure. In all instances neutrophils were greater than $95 \%$ pure and viability was greater than $95 \%$ when assessed by trypan blue exclusion.

\section{CELL STIMULATION}

Neutrophils in RPMI $\left(1 \times 10^{7} / \mathrm{ml}\right)$ were stimulated by incubation for 15 minutes at $37^{\circ} \mathrm{C}$ with the appropriate stimuli $(0 \cdot 1 \mu \mathrm{g} / \mathrm{ml}$ phorbol myristate acetate (PMA), 10\% v/v cell free synovial fluid) or primed by incubation for 60 minutes at $37^{\circ} \mathrm{C}$ with $50 \mathrm{U} / \mathrm{ml} \mathrm{GM}$-CSF.

\section{RECEPTOR ANALYSES}

Monoclonal antibodies

The following monoclonal antibodies were used: Leu11a (CD16), Leu15 (CD11b), and CD35 from Becton and Dickinson; IV.3 (CD32) and CD64 (322) antibodies were obtained from Medarex. Antibodies to CD11b recognise epitopes on the $\alpha$ chain of the CR3 receptor. CD35 is an epitope of the CR1 receptor, whereas CD16 and CD32 recognise the low and intermediate affinity receptors for the Fc portion of IgG respectively. Antibodies to CD64 recognise Fc RI, the high affinity receptor which is usually only expressed on neutrophils after culture in the presence of interferon $\gamma$. 3108 positive cells avidly bind formyl peptides and show membrane depolarisation after cell activation, ${ }^{15}$ whereas 31D8 negative cells do not respond functionally to fMLP. ${ }^{16}$

\section{Staining}

Neutrophils were suspended in phosphate buffered saline (PBS) $/ 1 \%$ bovine serum albumin (BSA) (globulin free) $/ 0.1 \%$ sodium azide, $\mathrm{pH} 7 \cdot 2$ and receptor expression was measured by a standard indirect immunofluorescence technique using FITC labelled goat antimouse immunoglobulin (Becton and Dickinson) as a second layer: both first and second layer antibodies were added at saturating concentrations. In all experiments non-immune mouse immunoglobulin of the appropriate isotype was included as class specific first layer controls. Stained cells were fixed in 1\% paraformaldehyde in PBS and analysed using a Becton and Dickinson FACS
Analyser I and a Consort 30 computer and software. The modal fluorescence was proportional to the number of antigenic sites on each cell for each individual antibody. Fluorescence distributions represented a total of 5000 gated events.

\section{STATISTICS}

Differences between the expression of receptors on neutrophils in the peripheral blood of patients and in control subjects was studied using the Mann-Whitney $U$ test for independent samples. The Wilcoxon matched pairs signed rank test was used to compare the expression of the receptors on the synovial fluid cells with their paired peripheral blood cells from the same patients. Results are expressed as median (interquartile range) responses.

\section{REAGENTS}

Recombinant human GM-CSF (97\% purity) was a non-glycosylated peptide from Glaxo and had an activity of $>1.5 \mathrm{MU} / \mathrm{mg}$ protein in the AML-193 proliferation assay. Sodium azide and globulin free BSA were obtained from Sigma. The Ficoll-Paque was from Pharmacia and RPMI was from Flow Laboratories.

\section{Results}

EXPRESSION AND MODULATION OF MEMBRANE ANTIGENS IN CONTROL PERIPHERAL BLOOD NEUTROPHILS

When neutrophils isolated from the peripheral blood of healthy controls were primed by incubation in the presence of the cytokine GMCSF $(50 \mathrm{U} / \mathrm{ml})$ an increased expression of the receptor CD11b (the $\alpha$ chain of the complement receptor CR3) was observed as indicated by an increase in fluorescence intensity for each cell (fig 1A). Expression of CD16 and 31D8 was not significantly altered when the cells were exposed to this cytokine in vitro (fig 1B-D).

Activation of neutrophils with PMA resulted in greater increases in CD11b expression than in primed (fig 1A and 1B) cells whereas CD16 (fig $1 \mathrm{C}$ and 1D) and 31D8 (fig $1 \mathrm{E}$ and $1 \mathrm{~F}$ ) expression decreased. In vitro priming and activation of the cells had no significant effect on the expression of CD64 and CD32 (Fcy RI and II respectively) under the experimental conditions used (maximum incubation time of 4 hours, data not shown). When blood neutrophils were incubated for 18 hours with cell free synovial fluid five of seven synovial fluid samples showed a slight increase in CD64 expression (data not shown).

MEMBRANE ANTIGEN EXPRESSION IN PERIPHERAL BLOOD AND SYNOVIAL FLUID NEUTROPHILS

No significant changes were observed in the percentage of neutrophils expressing the CD32 (Fcy RII) and CD35 (CR1) receptors in peripheral blood neutrophils of the rheumatoid 


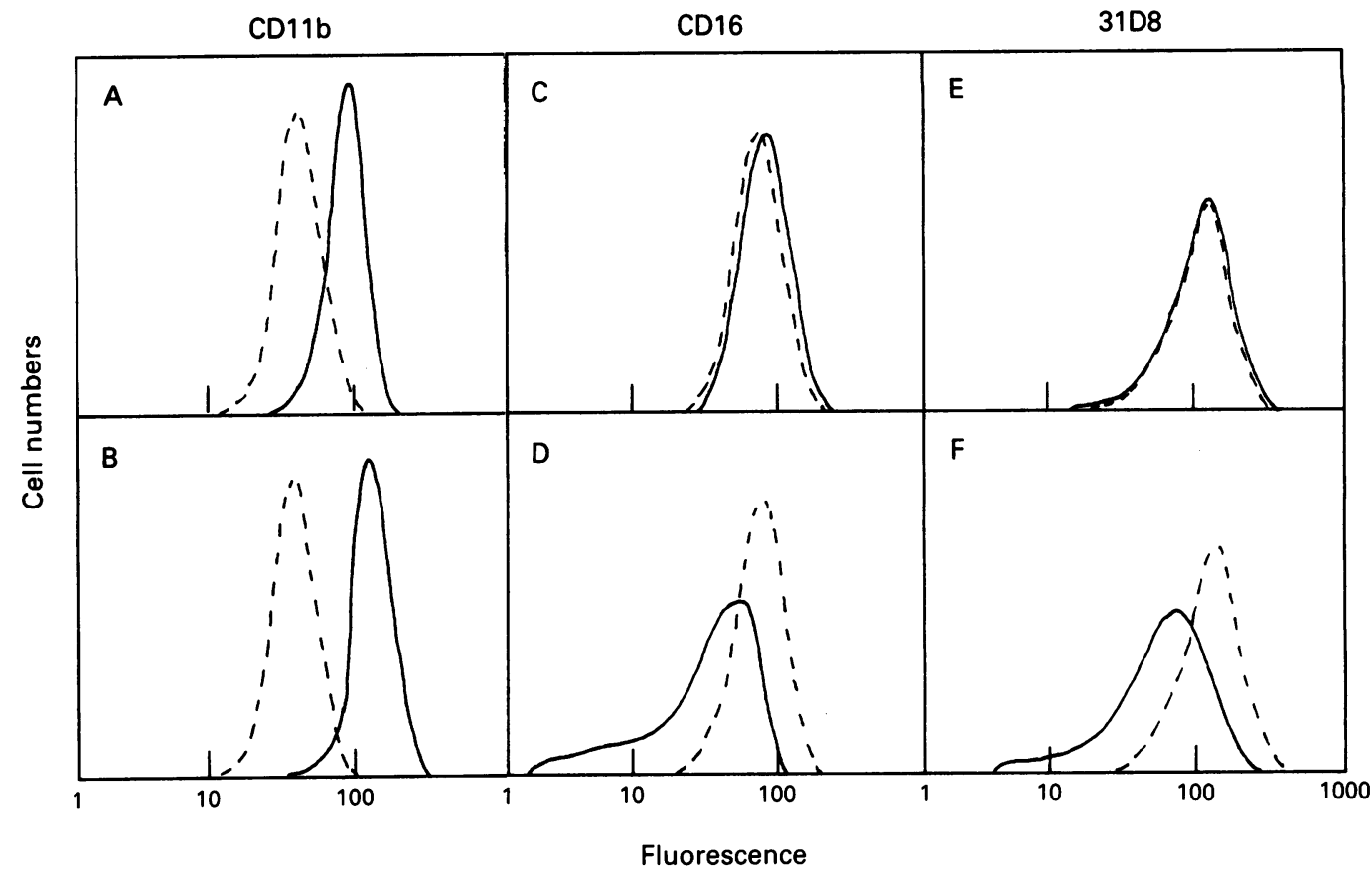

Figure 1 Receptor expression in primed and activated bloodstream neutrophils. Neutrophils isolated from the blood of healthy controls were resuspended in RPMI $\left(1 \times 10^{7} / \mathrm{ml}\right)$ and incubated at $37^{\circ} \mathrm{C}$ in the absence $(---)$ or presence $(\longrightarrow)$ of $0 \cdot 1 \mu \mathrm{g} / \mathrm{ml}$ phorbol myristate acetate $(B, D, F)$ for 15 minutes or with $50 \mathrm{U} / \mathrm{ml}$ granulocyte-macrophage colony stimulating factor $(\longrightarrow$ for 60 minutes $(A, C, E)$. After these incubations the cells were stained for fluorescence activated cell sorting analysis as described under Subjects and methods. Similar results were obtained in 10 other experiments.

patients compared with those of healthy controls (table 1). Table 2 indicates that although the median values for $\mathrm{CD} 11 \mathrm{~b}$ expression are slightly higher and CD16 and $31 \mathrm{D} 8$ slightly lower in the peripheral blood neutrophils from rheumatoid patients these differences again did not reach significance.

Table $1 C D 32$ and $C D 35$ receptor expression in neutrophils

\begin{tabular}{llll}
\hline Receptor & $\begin{array}{l}\text { Control } \\
\text { blood } \\
(n=5)\end{array}$ & \multicolumn{2}{l}{ Rheumatoid arthritis $(n=12)$} \\
\cline { 3 - 4 } & Blood & Synovial fluid \\
\hline CD32 & $80(80-98)$ & $75(61-93)$ & $16(11-48)^{\star}$ \\
CD35 & $35(34-40)$ & $22(12-50)$ & $15(7-26)^{\star}$ \\
\hline
\end{tabular}

Neutrophils were isolated from the bloodstream of healthy controls and the blood and synovial fluid of patients with rheumatoid arthritis (RA). Cells were stained for the expression of CD32 (Fcy RII) and CD35 (CR1) as described under Subjects and methods. There were no significant differences in the expression in bloodstream neutrophils of healthy controls or patients with RA, but synovial fluid neutrophils had statistically significant decreased expression as determined using the Wilcoxon $t$ matched pairs signed ranks test. Values presented are percentage cell population expressing the receptor. receptor.
${ }^{2}<0.005$.

Table 2 CD11b, CD16, and 31D8 expression in blood and synovial fluid neutrophils

\begin{tabular}{llll}
\hline Receptor & $\begin{array}{l}\text { Control } \\
\text { blood } \\
(n=15)\end{array}$ & Rheumatoid arthritis $(n=12)$ & \\
\cline { 2 - 4 } & $0 \cdot 9 \times 10^{5}$ & Blood & Synovial fluid \\
\hline CD11b & $\left((0.5-1 \cdot 1) \times 10^{5}\right)$ & $1 \cdot 2 \times 10^{5}$ & $1 \cdot 9 \times 10^{5}$ \\
& $1 \cdot 4 \times 10^{5}$ & $\left((0 \cdot 8-1 \cdot 9) \times 10^{5}\right)$ & $\left((1 \cdot 2-2 \cdot 5) \times 10^{5}\right)^{\star}$ \\
CD16 & $\left((1.3-2 \cdot 0) \times 10^{5}\right)$ & $1 \cdot 0 \times 10^{5}$ & $0 \cdot 8 \times 10^{5}$ \\
& $2 \cdot 8 \times 10^{5}$ & $\left((0 \cdot 8-1 \cdot 5) \times 10^{5}\right)$ & $\left((0 \cdot 7-1 \cdot 0) \times 10^{5}\right)^{\star}$ \\
$31 D 8$ & $\left((2 \cdot 1-3 \cdot 5) \times 10^{5}\right)$ & $2 \cdot 0 \times 10^{5}$ & $1 \cdot 3 \times 10^{5}$ \\
& $\left((1 \cdot 6-2 \cdot 5) \times 10^{5}\right)$ & $\left((1 \cdot 1-1 \cdot 5) \times 10^{5}\right)^{\star}$ \\
\hline
\end{tabular}

Neutrophils were isolated from the bloodstream of healthy controls and the bloodstream and synovial fluid of patients with rheumatoid arthritis (RA). Cells were stained for CD11b, CD16, and $31 \mathrm{D} 8$ as described under Subjects and methods. There were no significant differences in expression of bloodstream neutrophils from controls or patients with RA, whereas synovial fluid neutrophils had statistically significant decreased expression of CD16 and 31D8, but an increased expression of $C D 11 b$, as determined by the Wilcoxon $t$ matched pairs signed ranks test. Value presented are the median fluorescence values with figures in parentheses indicating the interquartile range. ${ }^{\star} \mathrm{p}<0.005$.
Neutrophils isolated from the synovial fluid of rheumatoid patients showed a significant decrease in the percentage of cells recognised by antibodies against CD32 (Fc $\gamma$ RII; $\mathrm{p}<0.005)$ and CD35 (CR1; $\mathrm{p}<0.005)$ compared with their peripheral blood counterparts (table 1). The percentage of synovial neutrophils expressing CD11b, CD16, and 31D8 did not differ significantly from the paired peripheral blood neutrophils (data not shown) but there was an increase in the number of CD11b (CR3) receptors expressed on the synovial neutrophils relative to paired bloodstream cells (table 2; $\mathrm{p}<0.005$ ). In addition, there was a significant decrease in the expression of CD16 (Fcy RIII) and 31D8 on the synovial neutrophils compared with paired bloodstream cells (table 2, $\mathrm{p}<0.005$ ).

The neutrophils from the synovial fluid of a patient with seronegative arthritis showed increased expression of CD11b and a decrease in the expression of CD16 and 31D8 compared with their peripheral blood neutrophils. There was also a decrease in the percentage of cells expressing CD35 and CD 32. These changes mirrored those observed for the seropositive patients. The patient with psoriatic arthritis showed a slight decrease in CD16 and 31D8 expression, but no significant changes in the other antigens studied.

CHANGES IN RECEPTOR EXPRESSION OF PERIPHERAL BLOOD NEUTROPHILS IN RESPONSE TO SYNOVIAL FLUID

When control (unprimed) bloodstream neutrophils were incubated for 15 minutes at $37^{\circ} \mathrm{C}$ with cell free synovial fluid from a patient with RA, expression of CD1lb was upregulated (fig $2 \mathrm{~A}$ ). In contrast, fluorescence distributions after staining for CD16 (Fcy 


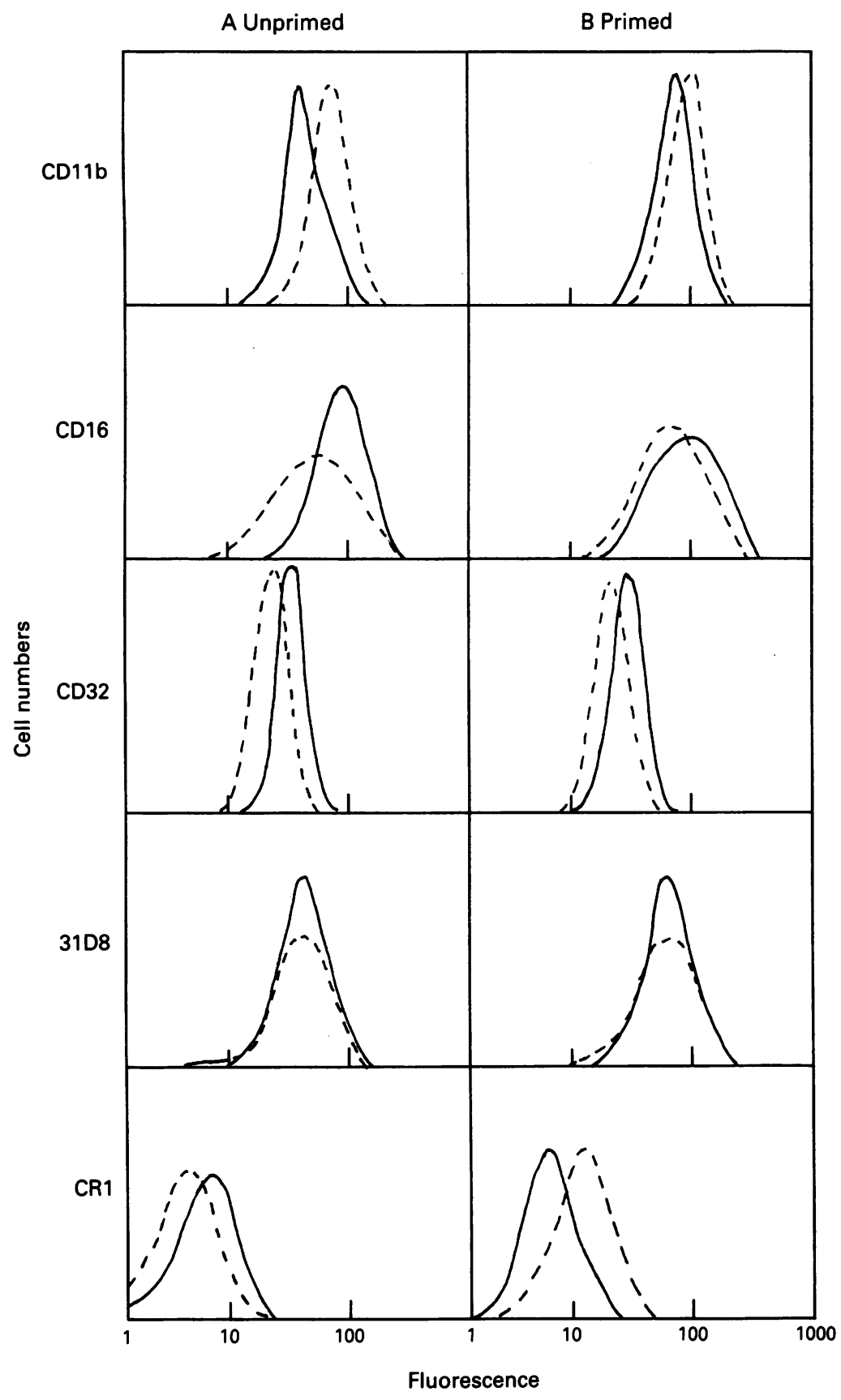

Figure 2 Effect of synovial fluid on receptor expression in bloodstream neutrophils. (A) Neutrophils were incubated in the absence $(-\rightarrow)$ or presence $(--)$ of $10 \%$ cell free synovial fluid at $37^{\circ} \mathrm{C}$ for 15 minutes. (B) Cells were incubated at $37^{\circ} \mathrm{C}$ for 60 minutes with $50 \mathrm{U} / \mathrm{ml}$ granulocyte-macrophage colony stimulating factor and then incubated for a further 15 minutes in the absence $(\longrightarrow)$ or presence $(--)$ of $10 \%$ cell free synovial fluid before staining for fluorescence activated cell sorting analysis. Similar results were obtained in four other experiments using synovial fluid samples from different patients and neutrophils from different controls.

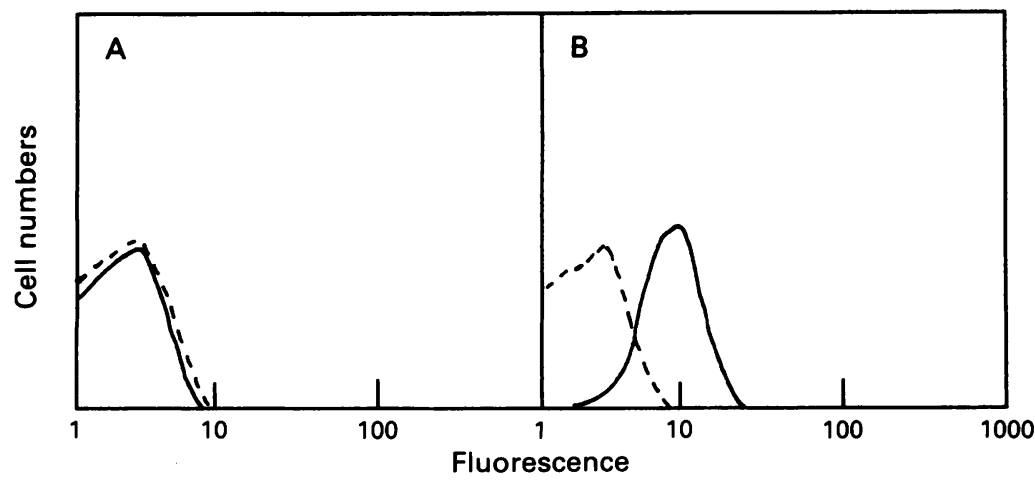

Figure 3 Fcy RI expression in neutrophils. Neutrophils were isolated from the synovial fluid of patients with rheumatoid arthritis and stained for the expression of Fcy RI using monoclonal antibody $322(\longrightarrow)$ or the non-immune isotype control monoclonal antibody $(--)$. The fluorescence distribution pattern in $(A)$ was obtained in five of 11 patients, whereas the pattern shown in $B$ was observed in six of 11 patients.
RIII), CD32 (Fcy RII), and 31D8 were all decreased on exposure of the cells to synovial fluid. These decreases may represent decreased expression of receptors as they become internalised or shed (especially the phosphatidylinositol linked CD16 and 31D8) or else because binding of monoclonal antibodies is blocked by ligands present in the synovial fluid (e.g. immunoglobulins interfering with the binding of $\mathrm{F}_{\mathrm{c}} \gamma \mathrm{R}$ ).

When control blood neutrophils were primed with GM-CSF (fig 2B) for one hour before the addition of synovial fluid, some differences were noted. Firstly, although priming induced an increased expression of $\mathrm{CD} 11 \mathrm{~b}$, the addition of synovial fluid resulted in a further increase in expression. Secondly, whereas synovial fluid downregulated CD 35 in unprimed cells, it upregulated expression in primed cells. These data indicate that whereas synovial fluid induces some effects on neutrophil receptor expression that resemble those which occur during priming in vitro, there are additional effects which may be attributable only to factors which cause activation through other mechanisms. Similar results were obtained in four other experiments using synovial fluid from different patients and control neutrophils from different donors.

\section{Fc $\gamma$ RI EXPRESSION}

Bloodstream neutrophils do not express CD64 (Fcy RI), the receptor with a high affinity for monomer IgG. This receptor is only expressed after incubation of cells with interferon $\gamma^{9}$ and the process requires activated de novo biosynthesis: incubation periods in excess of 16 hours are required before the receptor is detectable on the cell surface. In all bloodstream neutrophil preparations from controls or patients with RA, no expression of CD64 expression (using monoclonal antibody 322) could be detected. Furthermore, in five of 11 patients with RA, neutrophils in the synovial fluid expression of this receptor could not be detected (fig 3A). In six of 11 patients expression was detected, however (fig 3B). This observation indicates that these latter neutrophils have been exposed to factor(s) within the synovial fluid which have selectively activated gene expression.

\section{Discussion}

Neutrophil responses can be evoked by a variety of particulate and soluble stimuli which effect cell activation by first binding to specific cell surface receptors. Neutrophil responses in vivo are regulated by the levels of expression of these surface receptors and how they are coupled to their respective signal transduction systems. Some factors which have specific receptors on the neutrophil surface include $\mathrm{C} 5 \mathrm{a}$, leukotriene $\mathrm{B}_{4}$, platelet activating factor, IgG, and interleukin 8 , and these have been implicated in the pathology of inflammatory joint disease. ${ }^{1718}$ In addition, neutrophil function may. be regulated by a variety of cytokines including tumour necrosis factor ${ }^{19}$ 
and GM-CSF. ${ }^{11}$ The synovium itself is the source of a variety of inflammatory mediators such as arachidonic acid metabolites, vasoactive amines, platelet activating factor, and complement cleavage products, and there is also local production of cytokines within the joint. $^{1}$ Furthermore, immune complexes present within rheumatoid joints are probably important in the activation of infiltrating neutrophils via $F_{c} \gamma$ receptors. ${ }^{20}$ Thus the levels of expression of neutrophil receptors within synovial fluid give an indication of the functional status of these cells and will also give an indication of their past history.

Several lines of evidence now point to the fact that neutrophils within the synovial fluid of patients with RA have been exposed to priming and activating factors in vivo. ${ }^{52}$ In this study we have used FACS analysis to measure the expression of plasma membrane receptors and compared the results of paired bloodstream and synovial fluid cells with those obtained after bloodstream cells had been primed, activated, or aged in vitro. It has been shown elsewhere that the isolation procedures used to purify neutrophils can sometimes affect the expression of some plasma membrane receptors. ${ }^{22}{ }^{23}$ Therefore, in this study we used the dextran/Ficoll isolation procedure to isolate blood and synovial fluid neutrophils because other methods (e.g. centrifugation on MonoPoly-Resolving Medium) are not always successful for the isolation of synovial fluid neutrophils. Comparison of receptor expression in bloodstream neutrophils from healthy controls did not reveal any statistically significant differences with those from patients with RA. Synovial fluid neutrophils, however, showed gross changes in receptor expression compared with paired bloodstream cells from the same patient. The observations for CD11b (CR3) confirm earlier reports, ${ }^{20}$ but additionally we have focused on the expression of receptors for Fc $\gamma$ as these are likely to be the receptors responsible for activation of reactive oxidant generation by synovial fluid neutrophils. $^{2425}$

Synovial fluid neutrophils showed a decreased expression of CD32 (Fc $\gamma$ RII) and CD16 (Fcy RIII) compared with paired bloodstream cells. As the expression of CD32 decreases only slightly during priming, activation, or aging, however, decreased staining of synovial fluid neutrophils probably indicates that monoclonal antibody binding is 'blocked' by ligands (e.g. immune complexes) present within the synovial fluid. Such ligand binding may also account, in part, for the decreased staining of CD16, but this receptor (and 31D8) is also shed from the plasma membrane during activation (fig 1 ) and this process may contribute to the decreased expression. Upregulation of CD11b in synovial fluid neutrophils is indicative of priming or activation, or both. The observation that a short incubation of primed or unprimed bloodstream neutrophils with cell free synovial fluid induces these patterns of receptor expression indicates that these changes in receptor expression can occur rapidly as newly recruited bloodstream neutrophils infiltrate inflamed joints.

Of considerable interest and importance is the finding that over half of the synovial fluid neutrophil samples express to varying degrees the high affinity IgG receptor, CD64 (Fcy RI). This receptor is not expressed by bloodstream neutrophils but is induced when protein biosynthesis is selectively upregulated during exposure to agents such as interferon $\gamma .{ }^{9}$ To determine if factors within synovial fluid could activate the expression of CD64, we incubated blood neutrophils for 18 hours with cell free synovial fluid. Five of seven synovial fluid samples tested induced a slight increase in CD64 expression. Thus it appears that synovial fluid may selectively activate gene expression in newly recruited neutrophils and further work is clearly needed to confirm this observation. Exposure of blood neutrophils to agents such as interferon $\gamma,{ }^{26} \mathrm{GM}-\mathrm{CSF},{ }^{27}$ or $\mathrm{G}-\mathrm{CSF}^{28}$ induces a rapid and selective increase in neutrophil protein biosynthesis which results in an enhanced ability to generate reactive oxidants, continued expression of key cellular components such as receptors, extended viability, and the generation of secondary cytokines. ${ }^{29-31}$ We therefore propose that synovial fluid neutrophils have been exposed to agents within synovial fluid which have resulted in such a selective increase in protein biosynthesis. If this phenomenon has occurred within inflamed joints then our current understanding of neutrophil function in disease pathology is grossly underestimated. Further work is necessary to identify the factors within synovial fluid which may be responsible for the regulation of receptor expression and activation of CD64 expression and also to assess the full biosynthetic activity of synovial fluid neutrophils so that their full role in disease pathology can be appreciated.

We thank the Arthritis and Rheumatism Council and Mersey Regional Health Authority for generous financial support. The monoclonal antibody $31 \mathrm{D} 8$ was a kind gift of Dr Krause, Hartford Hospital, Connecticut, USA.

1 Lipsky P E, Davis L S, Cush J J, Oppenheimer-Marks N. The role of cytokines in the pathogenesis of rheumatoid arthritis. Springer Semin Immunopathol 1978; 11: 125-62.

2 Gale R, Bertouch J V, Bradley J, Roberts-Thomson R J. Direct activation of neutrophil chemiluminescence by rirect activation of neutrophil chemiluminescence by 42: $158-62$.

3 Follin P. The primed neutrophil - a friend or foe in inflammation. Linkoping University Medical Dissertations No 335: 1991 .

4 Merry P, Winyard P G, Morris C J, Grootveld M, Blake D $R$. Oxygen free radicals, inflammation and synovitis: the current status. Ann Rheum Dis 1989; 48: 864-70.

5 Nurcombe H L, Bucknall R C, Edwards S W. Neutrophils isolated from the synovial fluid of patients with rheumatoid arthritis: priming and activation in vivo. Ann Rheum Dis 1991; 50: 147-53.

6 Edwards S W, Hughes V, Barrow J, Bucknall R. Immunological detection of myeloperoxidase in synovial fluid from patients with rheumatoid arthritis. Biochem $\mathcal{f}$ 1988; 250: 81-5.

7 Berger M, O'Shea J, Cross A S, et al. Human neutrophils increase expression of $\mathrm{C} 3 \mathrm{bi}$ as well as $\mathrm{C} 3 \mathrm{~b}$ receptors upon incrivation. $\mathcal{F}$ Clin Invest 1984; 74: 1566-71.

8 Huizing T W J, van der Schoot E C, Jost C, et al. The PIlizinga $\mathrm{T}$ J, van der Schoot $\mathrm{E} C$, Jost $\mathrm{C}$, et al. The $\mathrm{PI}$ linked receptor FcRIII is released

9 Perussia B, Dayton E, Lazarus R, Fanning V, Trinchieri G. Immune interferon induces the receptor for monomeric $\mathrm{IgG}_{1}$ on human monocyte and myeloid cells. $\mathcal{F}$ Exp Med 
1985; 158: 1092-113.

10 Weisbart R H, Golde D W, Clark S C, Wong G G, Gasson J C. Human granulocyte-macrophage colony stimulating factor is a neutrophil activator. Nature $1985 ; 314$ : 361-3.

11 Atkinson Y H, Marasco W A, Lopez A F, Vadas M A Recombinant human tumour necrosis factor $\alpha$ regulation of $\mathrm{N}$-formyl methionyl leucyl phenylalanine. Receptor affinity and function on human neutrophils. $\mathcal{f}$ Clin Invest 1988; 81: 759-65.

12 Weisbart R H, Golde D W, Gasson J C. Human GMCSF modulates the number and affinity of neutrophil $\mathrm{f}-\mathrm{Met}-$ Leu-Phe receptors. F Immunol 1986; 137: 3584-7.

13 Edwards S W, Say J E, Hart C A. Oxygen-dependent killing of Staphlococcus aureus by human neutrophils. $\mathcal{f} \mathrm{Gen}$ Microbiol 1987; 133: 3591-7.

14 Feldmann M, Brennan F M, Chantry D, et al. Cytokine production in the rheumatoid joint: implications for treatment. Ann Rheum Dis 1990; 49: 480-6.

15 Seligmann B E, Chused T M, Gallin J I. Binding of fluoresceinated chemoattractant peptide to human neutrophils is heterogeneous and correlated with heterogeneous stimulation of membrane potential changes. $\mathcal{F}$ Cell Biol 1982; 95: 21133.

16 Seligmann B E, Melnick D A, Malech H L, Gallin J I. Identification of two subpopulations of neutrophils using Identification of two subpopulations of neutrophils using functional responsiveness. $\mathcal{F}$ Cell Biol 1983; 97: 1580 .

17 Sandborg R R, Smolen J E. Early biochemical events in leukocyte activation. Lab Invest 1988; 59; 300-20.

18 Baggiolini M, Walz A, Kunkel S L. Neutrophil-activating peptide-1/interleukin 8 , a novel cytokine that activates neutrophils. F Clin Invest 1989; 84: 1045-9.

19 Berkow R L, Wang D, Larrick J W, Dodson R W, Howard $\mathrm{J} H$. Enhancement of neutrophil superoxide production by preincubation with recombinant human tumor necrosis factor. F Immunol 1987; 139: 3783-91.

20 Emery P, Lopez A F, Burns G F, Vadas M A. Synovial fluid neutrophils of patients with rheumatoid arthritis have membrane antigen changes that reflect activation. $A n n$ Rheum Dis 1988; 47: 34-9.

21 Dularay B, Elson C J, Dieppe P A. Enhanced oxidative response of polymorphonuclear leukocytes from synovial fluids of patients with rheumatoid arthritis. Autoimmunity 1988; 1: 159-69.

22 Kuijpers W, Tool A T J, van der Schoot C E, et al.
Membrane surface antigen expression on neutrophils: a reappraisal of the use of surface markers for neutrophil activation. Blood 1991; 78: 1105-11.

23 Watson F, Robinson J J, Edwards S W. Neutrophil function in whole blood and after purification: changes in receptor expression, oxidase activity and responsiveness to cytokines. Biosci Rep 1992; 12: 123-33.

24 Robinson J J, Watson F, Bucknall R C, Edwards S W. Stimulation of neutrophils by insoluble immunoglobulin goregates from synovial fluid of patients with rheumatoid arthritis. Eur F Clin Invest 1992; 22: 314-8.

25 Robinson J J, Watson F, Bucknall R C, Edwards S W. Activation of neutrophil reactive-oxidant production by synovial fluid from patients with inflammatory joint synovial fluid from patients with inflammatory joint
disease. Soluble and insoluble immunoglobulin disease. Soluble and insoluble immunoglobulin aggregates activate different pathways in p
unprimed cells. Biochem $\mathcal{F}$ 1992; 286: 345-51.

26 Humphreys J M, Hughes V, Edwards S W. Stimulation of neutrophil protein synthesis by $\gamma$-interferon. Biochem Pharmacol 1989; 38: 1241-6.

27 Edwards S W, Holden C S, Humphreys J M, Hart C A. Granulocyte-macrophage colony-stimulating factor (GMCSF) primes the respiratory burst and activates protein biosynthesis in human neutrophils. FEBS Lett 1989; 256: 62-9.

28 Humphreys J M, Rugman F P, Davies J M, Mimnagh P, Hart C A, Edwards S W. Effects of recombinant human granulocyte colony-stimulating factor on neutrophil function in vitro and in vivo following chemotherapy and autologous bone marrow transplantation. 7 Clin Lab Immunol 1992; 34: 55-61.

29 Edwards S W, Watson F, MacLeod R, Davies J. Receptor expression and oxidase activity in human neutrophils: regulation by granulocyte-macrophage colonystimulating factor and dependence upon protein stimulating factor and dependence upor

30 Lindemann A, Riedel D, Oster W, et al. Granulocyte macrophage colony-stimulating factor induces interleukin 1 production by human polymorphonuclear neutrophils. f Immunol 1988; 140: 837-9.

31 Lindemann A, Riedel D, Oster W, Ziegler-Heitbrock H W L, Mertlesmann R, Herrmann F. Granulocytemacrophage colony-stimulating factor induces cytokine secretion by human polymorphonuclear leukocytes. $\mathcal{F}$ Clin Invest 1989; 83: 1308-12. 